\title{
PROJEKTIRANJE PREOBLIKOVANJA STRUKTURE SIL VOJSKE
}

\author{
PROJECTING THE TRANSFORMATION \\ OF MILITARY FORCE STRUCTURE
}

Povzetek Prispevek obravnava aktualna vprašanja projektiranja strukture sil, kar v tujini pojmujejo kot force planning oziroma programmed forces. Njegov namen pa je poleg predstavitve metodologije in procesa projektiranja strukture sil opozarjanje, da je nujen sprejem primerljive metodologije pri pristopu $\mathrm{k}$ oblikovanju razvojnih programov in preoblikovanju strukture sil Slovenske vojske. Tematika je v Slovenski vojski skoraj v celoti neraziskana, zato se zgledovanje in primerjanje z organizacijsko in menedžersko teorijo ter dostopnimi tujimi viri pojavljata kot nuja. Metodologija projektiranja strukture sil vojske v Republiki Sloveniji še ni v celoti izoblikovana in uveljavljena v praksi. Dostopni so nekateri modeli in tehnike, ki jih uporabljajo v industrijsko najrazvitejših državah v podporo projektiranju, ter za to usposobljen del kadra.

Ključne Reorganizacija in preoblikovanje, projektiranje organiziranosti, defense planning, besede force planning, projektiranje preoblikovanja strukture sil, preoblikovanje Slovenske vojske.

Abstract The article deals with the current questions of force structure projecting, which is abroad defined in terms of force planning or programmed forces. In addition to the presentation of methodology and the process of projecting force structure, the article's aim is to point out to the need for the adoption of a comparable methodology when approaching to the formation of development programmes and the reformation of Slovenian Armed Forces (SAF) structure re-formation. In the SAF, this topic is almost completely unexplored. Modelling upon and comparison with the organizational and manager theory and available foreign resources thus appears necessary. The methodology of force structure projecting in the Republic of Slovenia has not been completely formed and put into practice. There are some models and techniques available, used in industrially more developed countries in support of the projecting, as well as a group of adequately trained personnel. 
Key words Reorganization and re-formation, organizational projecting, defense planning, force planning, the process of projecting force structure reorganization, reorganization of Slovenian Armed Forces.

Uvod Preoblikovanje strukture sil vojske je odsev ogroženosti in drugih vplivov okolja, tehnično tehnološkega razvoja, funkcijskih potreb in življenjskega cikla določene vojaške strukture (enote, rodu, zvrsti). Ni vojaške organiziranosti, ki bi bila primerna za ves čas. Zato jo je treba nenehno prilagajati spremembam okolja in ogroženosti, spremembam v tehnologiji delovanja, vrstam in značilnostim bojnih sistemov ter fazam razvojnega cikla vojske. Navedeno pomeni, da je projektiranje organiziranosti strukture sil stalen, ponavljajoč se proces.

S sedanjim preoblikovanjem je tudi Slovenska vojska na razvojni prelomnici in pred pomembnimi izzivi. Te predstavljajo zlasti dejavnosti, povezane z njeno reorganizacijo in projektiranjem njene prihodnje strukture, ter dejavnosti in prizadevanja Republike Slovenije za vključitev v Nato. Pri tem je v ospredju vprašanje, kako oblikovati pravo strukturo in se izogniti nekritičnemu zgledovanju in kopiranju rešitev od drugod oziroma kako projektirati za prihodnost v razmerah, ko se okolje izredno hitro spreminja in je vedno težje predvidljivo.

\section{REORGANIZACIJA IN (ALI) PREOBLIKOVANJE}

Reorganizacija (preosnova, preureditev, preustroj) je spreminjanje organizacije in vzpostavljanje novih razmerij in struktur (Lipovec, 1987, str. 35). Nekateri avtorji načrtno spreminjanje organizacije definirajo kot organizacijski razvoj, za katerega sta značilna spreminjanje in inoviranje organizacije (Rozman, 1993, str. 190). Pri tem s spreminjanjem organizacije razumejo uveljavljanje novih zamisli, ki že obstajajo, z inoviranjem organizacije pa razumejo uveljavljanje novih, povsem na novo razvitih zamisli. Nekateri avtorji namesto inoviranja uporabljajo termin reinženiring. Reinženiring pojmujejo kot novo organizacijsko revolucijo, ki temelji na tem, da je treba staro organizacijo in njena načela preprosto zbrisati, odpraviti in začeti znova (Vila, 1997). Terminološka dilema glede reorganizacije in (ali) preoblikovanja obstaja tudi na obrambnem področju v svetu in pri nas ${ }^{1}$. Najpogosteje se z izrazom reorganization razume tako reorganizacija (spreminjanje) kot preoblikovanje (inoviranje) strukture sil, to pomeni, da se izraza uporabljata kot sinonima. Poleg tega izraz preoblikovanje na vojaškem področju najpogosteje prevajamo v reorganization.

Organizacijsko spreminjanje Slovenske vojske bo v prihodnosti povzročilo spreminjanje sedanjih organizacijskih in strukturnih elementov, pa tudi uvajanje povsem novih. Če se bomo tako kot v večini evropskih držav odločili za konceptualne spremembe (sprememba tipa vojaške organiziranosti zaradi drugačnega popolnjevanja vojske), bo treba zlasti preoblikovati (inovirati) strukturo sil.

1 Pri nas se v strateških in razvojnih dokumentih najpogosteje uporablja izraz preoblikovanje Slovenske vojske. 


\section{DEFENSE PLANNING IN FORCE PLANNING: NAČRTOVANJE OBRAMBNEGA SISTEMA IN NAČRTOVANJE SIL}

Defense planning in force planning sta pojma, ki se v angleški verziji uporabljata za opredelitev obrambnega načrtovanja in projektiranja organiziranosti obrambnega sistema ter načrtovanja sil in projektiranja organiziranosti vojaških sil. Prevod oziroma slovenska izraza bi bila načrtovanje obrambnega sistema in načrtovanje sil.

Treba je ločiti načrtovanje in projektiranje organiziranosti obrambnega sistema (obrambe) od načrtovanja in projektiranja organiziranosti vojaške organizacije (vojske). V industrijsko najrazvitejših državah je ta razmejitev prepoznavna, čeprav ostre ločnice v praksi med njima ni in se prepletata. Za projektiranje obrambnega sistema in obrambno načrtovanja se uporablja izraz defense planning ${ }^{2}$. Za projektiranje vojaške organiziranosti in načrtovanje sil pa se najpogosteje uporablja izraz force planning, redkeje programmed forces (Dictionary of military terms, 1995, str. 278). Pri force planningu je poudarek na določanju ciljev, doktrine, taktike in operatike, pri programmed forces pa na »programiranju« strukture sil. Isti vir uporablja za vojaško načrtovanje (delovanja) izraz military planning.

Defense planning pokriva potrebe institucionalno-političnega načrtovanja in obsega načrtovanje obrambne politike in strategije ter načrtovanje in programiranje (letno in večletno oziroma srednje- in dolgoročno) financiranja obrambe in upravljanja virov na eni strani ter projektiranje organiziranosti obrambnega sistema na drugi strani.

Dejavniki, ki določajo naravo defense planninga, so: nacionalni cilji, razpoložljivi viri, upravne in organizacijske značilnosti države, dojemanje grožnje in nasprotnika ter tehnologija s svojimi omejitvami. Pristopi in metodologija defense planninga so med državami različni ${ }^{3}$, čeprav obstaja veliko mehanizmov, zlasti znotraj držav članic Nata, in prizadevanj, npr. med članicami Partnerstva za mir, za doseganje njegove primerljivosti in transparentnosti. Izdelki defense planninga so praviloma akti, ki jih sprejema parlament ali vlada (zakoni, programi, smernice, proračuni ipd.), in so letni ali večletni oziroma dolgoročni. Izdelke pripravljajo posebne organizacijske enote znotraj obrambnega ministrstva ali (in) parlamenta.

Force planning obsega postopke načrtovanja in projektiranja sil kot odgovor na grožnjo in tveganja z doktrino, operatiko in taktiko, s strukturo sil ter z bojno sposobnostjo in zmogljivostjo sil. Naslanja se na defense planning, ki zagotavlja strategijo, oceno grožnje in scenarije s sprejemljivim tveganjem ter seveda razpoložljive finančne vire. Ima osrednjo vlogo v zagotovitvi razvoja sil in sposobnosti vojaških sil, potrebnih za njene različne naloge, ter predstavlja fokus za povezovanje delovanja in drugega načrtovanja (Boland, 1998, str. 32). Force planning izvajajo posebne organizacijske enote navadno v generalštabih. Redkeje

International Military and Defense Encyclopedia, 1993, str. 2144.

V ZDA uporabljajo tako imenovani PPBS (Planning, Programming and Budgeting System), ki ga je vpeljal

Robert McNamara že leta 1960. 
je združen z organizacijsko enoto, odgovorno za defense planning, s katero pa tesno sodelujeta. V načrtovalnem smislu je širši od projektiranja preoblikovanja strukture sil vojske, čeprav je to njegov najpomembnejši del.

Načrtovanje sil predstavlja celoto dejavnosti in postopkov, s katerimi se zagotavljata usklajenost in stabilnost njenega razvoja. Z načrtovanjem sil se dolgoročno in srednjeročno usmerjajo razvoj in spremembe obsega in organizacijske strukture, kadrovski sistem, opremljanje in modernizacija ter alokacija obrambnih virov.

\section{PROJEKTIRANJE ORGANIZIRANOSTI}

Zasnovanje in preosnovanje organiziranosti seuporabljajorazličniizrazi:projektiranje organiziranosti, modeliranje organiziranosti, organizacijska zgraditev, oblikovanje organiziranosti, organiziranje, strukturiranje itn. V slovenski organizacijski teoriji se najbolj uveljavlja izraz projektiranje modelov organiziranosti in to preučuje posebna znanstvena disciplina organizational design - projektiranje organizacije (Ivanko, 1999, str. 83). Naloga te organizacijske discipline je, da poskuša odgovoriti na vprašanja, kako mora biti organizirana organizacija, da bo uspešno delovala v danih razmerah. Preučitev in primerjava kažeta, da se je tudi pri projektiranju preoblikovanja strukture sil v vojski mogoče zgledovati po omenjeni znanstveni disciplini. Vse dileme pa s tem gotovo niso odpravljene. Pomembno vprašanje namreč je, ali gre pri projektiranju organiziranosti za plansko funkcijo ali funkcijo organiziranja. ${ }^{4}$ Organizacijska in menedžerska teorija pripisujeta vzpostavljanje razmerij in struktur funkciji organiziranja, z načrtovanjem pa razumeta predvsem zamišljanje celotnega poslovanja (delovanja) organizacije skupaj $\mathrm{z}$ določanjem planskih ciljev in delovanja.

Projektiranje preoblikovanja strukture sil v vojski je snovanje spreminjanja strukture organiziranosti vojske in njenega sistema vodenja $\mathrm{z}$ uporabo ustrezne metodologije in podpore. S projektiranjem preoblikovanja strukture sil v vojski razumemo najprej postopke načrtovanja sprememb strukture in zatem postopke organiziranja oziroma njihovo vzpostavljanje.

\section{VPLIVNI DEJAVNIKI ZA PROJEKTIRANJE PREOBLIKOVANJA STRUKTURE SIL}

V sedanjih razmerah je pri projektiranju preoblikovanja strukture sil treba upoštevati novo organizacijsko paradigmo vojske, ki je vedno bolj destrukcija stare in izraz vplivnih dejavnikov. Glavne značilnosti nove organizacijske paradigme vojske so:

\footnotetext{
Izraz projektiranje se največ uporablja v tehniki in izhaja iz latinskega izraza proiectum (projekt); ima ožji in širši pomen. V ožjem pomenu pod pojmom projektiranje razumemo načrt, skico, predlog za delo, postopek, $v$ širšem smislu pa pomeni vsako delotvorno zamisel, odločitev. Projektirati pomeni napraviti načrt, projekt. Projektiranje je torej reševanje sestavljenih problemov oziroma ustvarjalni proces, v katerem se na temelju osnovnih prvin in znanja oblikuje neki sistem. Ker je sistem organizirana celota, ni vsebinske razlike med organiziranjem in projektiranjem (Ivanko, 1999, str. 83).
} 
1. uporaba oboroženih sil je $\mathrm{v}$ sodobnih razmerah kompleksna in jo je mogoče razumeti le z upoštevanjem te kompleksnosti,

2. uvajanje sprememb v strukturi kadrovske sestave in profesionalizacija,

3. pripravljenost za hitro strukturno prilagajanje in raznolikost organizacijskih oblik,

4. večspektralnost oziroma uporaba sil v širokem spektru ogrožanj varnosti in

5. uveljavljanje večstranskega in večnacionalnega sestavljanja in uporabe sil.

Iz prej navedenega izhajata dve temeljni zahtevi za projektiranje preoblikovanja, to sta stabilnost in fleksibilnost organizacije. Stabilnost vojaške organizacije se izraža v ohranjanju bojne sposobnosti in zmogljivosti sil za izvajanje institucionalno določenih nalog, fleksibilnost pa $\mathrm{v}$ nenehnem strukturnem prilagajanju glede na vplivne dejavnike. Stabilnost organizacije in njena fleksibilnost sta v navideznem nasprotju, čeprav imata isti cilj v učinkovitosti organizacije. Zato je pri projektiranju organiziranosti treba iskati temu primerne organizacijske modele in rešitve.

Kot zelo pomembni je treba pri strukturiranju vojaških organizacij upoštevati tudi centralizacijo in decentralizacijo. Vprašanje centralizacije in decentralizacije v vojaški organizaciji ima več vidikov. Pri tem je v ospredju razmerje med njima oziroma razmejitev izvajanja posameznih postopkov in uresničevanja funkcij. Centralizacija odločanja v vojaški organizaciji ni dvomljiva, pomembna pa je z vidika disperzije pristojnosti po ravneh. Zelo pomembno je, da pri projektiranju strukture sil dosežemo organizacijsko ravnotežje med centralizacijo in decentralizacijo.

Izid organiziranja je organizacijska struktura. Pri oblikovanju organizacijske strukture je treba upoštevati zlasti štiri temeljne prvine. Te so: specializacija, standardizacija, koordinacija in avtoriteta. ${ }^{5}$

$\mathrm{V}$ vojaški organizaciji so pomembni trije vidiki avtoritete, in sicer enotnost ukazovanja, hierarhija in kontrolni razpon. Pri avtoriteti je treba razlikovati linijsko in štabno (funkcijsko) avtoriteto. Enotnost ukazovanja pomeni, da mora vsak element imeti enega vodjo. Hierarhija predstavlja čisto in nepretrgano verigo nadrejenosti in podrejenosti ter ukazovanja, ki povezuje posamezne elemente v organizaciji. Glede na število hierarhičnih ravni je organizacijska struktura lahko visoka ali nizka.

Velja prepričanje, da je kontrolni razpon glavni vidik organizacijske strukture. Mnogi teoretiki organizacije so se ukvarjali s preučevanjem optimalnega kontrolnega razpona in pri tem spoznali, da je za višje organizacijske ravni primernejši ožji razpon, za nižje organizacijske ravni pa širši razpon.

\footnotetext{
Specializacija je stopnja delitve skupne delovne naloge na posamezne delovne naloge. Specializacija je torej opredeljevanje posebnih nalog in njihovo dodeljevanje posameznikom ali skupinam. Standardizacija opredeljuje organizacijske postopke tako, da se delovne naloge opravljajo enotno in konsistentno. Koordinacija obsega formalne in neformalne postopke povezovanja dejavnosti, ki jih izvajajo posamezniki ali skupine $v$ organizaciji. Z vertikalno koordinacijo se določa število ravni, s horizontalno pa število organizacijskih podenot na določeni ravni. Avtoriteta je pravica delovati in odločati ter določa, kdo je komu odgovoren in kdo komu poroča (Možina et. al., 1994, str. 382).
} 
Vplivni dejavniki za organiziranje struktur so vsi tisti, ki neposredno ali posredno vplivajo na strukturiranje in oblikovanje organiziranosti. Organizacijska teorija razlikuje dve temeljni skupini vplivnih dejavnikov ${ }^{6}$ :

1. zunanje dejavnike in

2. notranje dejavnike.

Primerjava kaže, da je takšna delitev sprejemljiva tudi pri razvrščanju vplivnih dejavnikov za projektiranje organiziranosti strukture sil v vojski. ${ }^{7}$

Zunanji vplivni dejavniki so tisti, ki se pojavljajo v interakcijah vojaške organizacije z okoljem, v katerem deluje. Najpomembnejši so:

1. viri ogrožanja, obrambna politika in naloge vojske,

2. institucionalna organiziranost,

3. družbene vrednote,

4. financiranje obrambnih potreb,

5. zgodovinske okoliščine in tradicija,

6. razvoj znanosti in tehnike.

Pojavlja se vprašanje o obravnavanju ogroženosti kot izhodiščnega vplivnega dejavnika ter kako obravnavati ogroženost - kot samostojni dejavnik ali v povezavi s politiko in na tej podlagi določenimi nalogami vojske. Ogroženost je izhodiščni dejavnik in je ne glede na spremembe v okolju in njeno spreminjanje še vedno pretežno institucionalna. Je podlaga za snovanje politike, namembnosti in nalog vojske, to pa je izraženo v strateških in doktrinarnih dokumentih, s čimer kaže svoj institucionalni značaj. Ogroženost ima tudi svoje dejanske pojavne oblike, ki se spreminjajo. Problemi nastanejo takrat, ko je razlika med dejansko in institucionalno predvideno ogroženostjo prevelika in zato prihaja do organizacijskih in strukturnih neskladij v obrambnem sistemu in vojski. Zaradi tega so v vojski razviti mehanizmi za zagotavljanje stabilnosti organizacije ter ukrepi in postopki za preprečevanje presenečenja na eni strani in zagotavljanje že omenjene fleksibilnosti organizacijskih oblik na drugi strani.

Notranji vplivni dejavniki so posebnosti vojaške organizacije, ki izhajajo iz njenega notranjega okolja, njene strukture in razvitosti. Najpomembnejši so:

1. cilji in doktrina delovanja,

2. taktika in operatika uporabe sil,

\footnotetext{
Vplivni dejavniki za strukturiranje organiziranosti; Ivanko, 1999, str. 17-22, in Sikavica, 1991, str. 2.

Možen je tudi drugačen pristop. Po letu 1980 so ameriški raziskovalci organizacije razvili celostni model 7-S obravnavanja in spreminjanja organiziranosti sodobnih organizacij (Ivanko, 1999, str. 6). Sestavine modela so $v$ bistvu elementi kompleksne organiziranosti. Celostni model 7-S se imenuje zato, ker se vse njegove variable začenjajo s črko S. Te variable, v katere sta usmerjena obravnavanje in spreminjanje organiziranosti, so: (1) strategije /Strategy/, (2) strukture /Structure/, (3) sistemi /Systems/, (4) skupne vrednote /Shared values/, (5) sodelavci /Staff/, (6) slog ravnanja /Style/ in (7) sposobnosti, znanje in veščine /Skills/. Variabla (3) sistemi obsega: sistem načrtovanja (dolgoročnega, letnega in operativnega), informacijski sistem in sistem kontrole. Strategije, strukture in sistemi predstavljajo trde variable, nasprotno pa so tiste, na katere se znotraj organizacije laže vpliva, mehke variable, in sicer: skupne vrednote, sodelavci-osebje, slog delovanja ter sposobnosti, znanja in veščine. Celostni model 7-S ne negira notranjih in zunanjih dejavnikov, temelji pa na spoznanju, da organizacije dosegajo učinkovitost in uspešnost, če lahko spreminjajo organiziranost po vseh variablah sočasno.
} 
3. kadrovska struktura,

4. vodstvo,

5. motivacijska struktura,

6. vojaška tehnologija, ki je na razpolago,

7. vojaška infrastruktura,

8. velikost organizacije in

9. sposobnost preoblikovanja in prilagajanja.

\section{PROJEKTIRANJE PREOBLIKOVANJA STRUKTURE SIL VOJSKE}

Projektiranje preoblikovanja strukture sil je proces, sestavljen iz medsebojno povezanih postopkov, ki potekajo po določenih načelih in se izvajajo z metodami projektiranja. Navedel sem že, da s projektiranjem najprej razumemo postopke načrtovanja sprememb strukture in nato postopke organiziranja oziroma njihovega vzpostavljanja. V nadaljevanju bodo predstavljena tista določila organizacijske teorije, ki veljajo tudi za projektiranje preoblikovanja strukture sil v vojski.

Organizacijska teorija (Ivanko, 1999, str. 83) pozna dva pristopa k projektiranju modelov organiziranosti:

1. ad hoc pristop in

2. sistematično-načrtni pristop.

Za ad hoc pristop je značilno, da se organizacijski problemi rešujejo takrat, ko ti nastanejo. Takšni pristopi so največkrat zapozneli, ker gre za gašenje problemov. Nemalokrat takšen pristop povzroči še večje probleme, za obvladovanje katerih so potrebni še obsežnejši intervencijski ukrepi.

Sistematično-načrtni pristop k projektiranju organiziranosti je preventivni pristop $\mathrm{k}$ reševanju organizacijskih problemov. Projektiranja se lotevajo načrtno, da bi pravočasno odpravili disfunkcije, ki nastajajo. To pomeni, da se projektiranje preoblikovanja strukture sil pojavlja kot sistematičen in stalen proces. $\mathrm{V}$ vojaških organizacijah $\mathrm{v}$ vojnih razmerah večinoma uporabljajo ad hoc pristop pri spreminjanju organizacijske strukture sil. Zgodovina potrjuje, da je bilo zlasti neposredno pred vojnami in v vojnah veliko takšnih sprememb uspešnih. V mirnodobnih razmerah pa se lahko takšen pristop velikokrat spremeni v postopek improviziranja in eksperimentiranja. Zato za vojske kot kompleksne organizacije in sočasno velike finančne (proračunske) porabnike velja, da svojo strukturo spreminjajo in preoblikujejo tako, da dolgoročno načrtno uporabljajo za projektiranje organiziranosti sistematično-načrtni pristop. Dolgoročni načrtni pristop pomeni praviloma ciklično spreminjanje organiziranosti, povezano s tehnično-tehnološko modernizacijo sil in delovanja. ${ }^{8}$

\footnotetext{
Za ciklično spreminjanje strukture vojaških organizacij je značilno, da se cikli časovno krajšajo glede na dvigovanje stopnje tehnično-tehnološkega razvoja, to kaže na obratno sorazmernost. Do devetdesetih let je veljal desetletni cikel, po razpadu blokovske bipolarnosti pa se je prepolovil.
} 
Načela načrtnega pristopa k projektiranju preoblikovanja strukture sil so 9 :

1. obravnavanje projektiranja preoblikovanja strukture sil kot sestavnega dela načrtov organizacije in njenega razvoja;

2. uvajanje smotrnih organizacijskih rešitev, ki so povezane med seboj;

3. projektiranje preoblikovanja strukture sil z uporabo ustreznih metod in tehnik;

4. ustvarjanje potrebnih pogojev za uresničitev projekta spreminjanja strukture sil;

5. ustvarjanje organizacijske klime za izvajanje projekta in uresničitev sprememb.

Projektiranje preoblikovanja strukture sil v vojski zahteva sistematičen pristop, ki omogoča reševanje zapletenih organizacijskih problemov in temelji na izhodiščih, da se spoznajo trenutne razmere, da se rešitve usmerijo k problemom in njihovemu preseganju ter da koncipiranje rešitev poteka od grobega k detajlnim ob upoštevanju bojne sposobnosti ter zmogljivosti sil in stroškov.

Projektiranje preoblikovanja strukture sil v vojski opredelimo z naslednjimi fazami ${ }^{10}$ :

\section{Sprožanje projektiranja}

1. opredelitev strategije za preoblikovanje

2. opredelitev nalog, ki izhajajo iz strategije za preoblikovanje

3. opredelitev resursov (čas, kadri in sredstva) za preoblikovanje

4. ocena učinkov preoblikovanja

5. opredelitev organiziranosti za projektiranje preoblikovanja

\section{Ocenjevanje trenutne organiziranosti}

1. opredelitev metodologije raziskovanja obstoječe organiziranosti

2. preučitev obstoječe organiziranosti

3. analiza stanja in ugotovitev disfunkcij

4. oblikovanje (terapevtskih) ukrepov in priporočil ter dopolnitev strategije za preoblikovanje

\section{Oblikovanje modela organiziranosti}

1. postavitev načrta oblikovanja modela organiziranosti

2. oblikovanje modela organiziranosti - osnovni primer

3. preveritev predloga modela organiziranosti - osnovni primer

4. razvoj alternativ in njihova preveritev

5. izbor in dokončno oblikovanje modela organiziranosti

6. elaboriranje in potrditev projekta preoblikovanja

\section{Izvedba projekta preoblikovanja}

1. izdelava načrta izvedbe preoblikovanja

2. izdelava aktov za izvedbo preoblikovanja

3. priprava in poučevanje kadrov za izvedbo preoblikovanja

4. uvajanje organizacijskih sprememb

5. spremljanje in nadzor izvedbe

9 Povzeto in prirejeno po Ivanko, 1999, str 86.

${ }^{10}$ Povzeto in prilagojeno po Ivanko (od Buble), 1999, str. 102-103. 
Predstavitev faz postopka projektiranja preoblikovanja strukture sil nas opozarja na zahtevnost procesa. Ključna vprašanja projektiranja preoblikovanja so povezana z odločanjem v posameznih fazah oziroma ob njihovih zaključkih, s čimer se omogoča nadaljnji potek.

\section{PROJEKTIRANJE PREOBLIKOVANJA STRUKTURE SIL VOJSKE}

$\mathrm{S}$ postavitvijo strategije za izvedbo preoblikovanja ${ }^{11} \mathrm{v}$ prvi fazi se določijo cilji in naloge, ki izhajajo iz ciljev, ter oblikujejo zamisel in usmeritve za projektiranje ter izvedbo preoblikovanja. Toje naloga vodstva. Strategija za izvedbo preoblikovanja pa je tudi izhodišče za snovanje pristopa ter uporabo metod in orodja med projektiranjem. Strategija za izvedbo preoblikovanja predstavlja vhod v projektiranje preoblikovanja strukture sil. Pri oblikovanju strategije za preoblikovanje konceptualne, normativne in strateško-doktrinarne opredelitve in druga izhodišča usmerimo v cilje, zamisel in usmeritve za izvedbo ter naloge, ki jih je treba uresničiti pri projektiranju preoblikovanja strukture sil in pri preoblikovanju. Ob koncu prve faze je treba sprejeti odločitev o nadaljevanju projektiranja preoblikovanja ter dati usmeritev za preučitev in analizo obstoječe organiziranosti.

Ocenjevanje obstoječe organiziranosti je druga faza projektiranja preoblikovanja strukture sil. Njegov namen je analiza stanja, ugotovitev disfunkcij in oblikovanje ukrepov ter izhodišč za snovanje alternativ modelov organiziranosti v nadaljevanju procesa. Rezultati analize so podlaga za dopolnitev strategije za preoblikovanje. Sprejem ukrepov in izhodišč za preoblikovanje in dopolnitev strategije za preoblikovanje ob koncu druge faze ter odločitev o nadaljevanju projektiranja sprožita naslednjo fazo. Pri ocenjevanju obstoječe organiziranosti je treba ugotoviti, kakšne so alternative za njeno spreminjanje. To je pomembno zlasti takrat, kadar se odločamo za preoblikovanje oziroma reinženiring organizacije. Takrat v bistvu ugotavljamo in presojamo konceptualne možnosti. Ugotovitev alternativ je osnova za oblikovanje različic modelov organiziranosti.

V tretji fazi oblikujemo več modelov organiziranosti in najustreznejšega po potrditvi elaboriramo v projekt preoblikovanja strukture sil. Najprej se oblikuje osnovni primer (osnovna varianta) modela organiziranosti, nato se preskusi s podpornim orodjem, ki je na razpolago. Preskus pokaže prednosti in pomanjkljivosti glede na stroške in sposobnost ter zmogljivost sil, to pa je izhodišče za snovanje alternativ. S postavitvijo alternativ se postopek oblikovanja modela organiziranosti ponavlja tako, da se spreminjajo posamezni elementi na osnovnem primeru ali gradi popolnoma nov model. Oblikovanje več različic se med projektiranjem pojavlja kot temeljni pogoj za učinkovito odločanje o modelu organiziranosti. Potrditev izbrane različice omogoča dokončno oblikovanje modela organiziranosti in elaboriranje v projektu preoblikovanja.

\footnotetext{
"Menedžerska teorija uporablja izraz strategija (Rozman, 1993, str. 84). Pri nas bi takšno pojmovanje lahko bilo dvomljivo zaradi sprejete hierarhije dokumentov. V vsakem primeru gre za usmerjevalni dokument in sodi med akte vodenja vojske, zato bi ga imenovali Usmeritve za preoblikovanje ali Obvezne usmeritve za preoblikovanje.
} 
Ključne odločitve se sprejemajo v tej fazi; odvisno od metodologije in modelov za podporo odločanja so lahko sprotne ali ob posameznih presekih oziroma ob koncu oblikovanja projekta.

Izvedba preoblikovanja strukture sil poteka v četrti fazi in predstavlja aplikacijo projekta, obsega pa izdelavo načrta izvedbe, priprave za izvedbo, uveljavljanje sprememb ter spremljanje in nadzor uresničevanja projekta preoblikovanja.

V tej fazi je treba potrditi načrt izvedbe preoblikovanja in sprejeti odločitve o izvedbi preoblikovanja. Pozneje moramo glede na ugotovitve spremljanja in nadzora poteka zagotoviti sprejemanje korektivnih odločitev.

Projektiranje uvajanja sprememb lahko poteka ${ }^{12}$ :

1. z vrha navzdol,

2. od spodaj navzgor,

3. z obeh strani (bipolarno),

4. po smereh (klinih),

5. po jedrih (področjih).

Odločitev za eno izmed možnosti je odvisna od aktualnega stanja, ciljev in strategije za preoblikovanje strukture sil ter razpoložljivega časa za uresničitev sprememb.

\section{METODE PRI PROJEKTIRANJU}

Kompleksnost projektiranja zahteva izbiro in uporabo ustreznih metod. Z metodami izvajamo posamezne postopke pri projektiranju preoblikovanja strukture sil (ocenjujemo, analiziramo, načrtujemo in programiramo, simuliramo in preskušamo ipd.). Ravno kombinacija metod omogoča oblikovanje najučinkovitejše strukture.

Pri projektiranju strukture sil se najpogosteje uporabljajo kompleksna analitična in kompleksna matrična metoda projektiranja, klasična metoda projektiranja in sodobni računalniški programski paketi ali modeli, ki temeljijo na metodah operacijskih raziskav.

Pri projektiranju strukture sil v vojski je zaradi posnemanja oziroma prenosa določenih obstoječih organizacijskih oblik in struktur še vedno močno prisotna klasična metoda projektiranja. Ta temelji na prilagajanju obstoječih ali uveljavljenih modelov organiziranosti. Izbrani model organiziranosti adaptiramo in prilagodimo konkretni organizaciji, zatem pa analiziramo odmike stvarnega stanja organiziranosti glede na adaptirani vzorčni model.

\footnotetext{
12 Povzeto po Ivanko, 1999, str. 87: Strategiji pristopanja k projektiranju modelov organiziranosti.
} 
Kompleksna analitična metoda je namenjena predvsem analitičnemu ocenjevanju funkcij in organiziranosti, lahko pa se uspešno uporabi tudi za preoblikovanje in projektiranje novih modelov organiziranosti.

Kompleksna matrična metoda temelji na nalogi kot izhodišču za projektiranje modela organiziranosti. Delovanje organizacije se členi do takšne stopnje, da omogoča projektiranje makro-, mezo- in mikromodela organiziranosti in uporabo matrike za odločanje. Analiza in členitev nalog ter delovanja je nujno poprejšnje opravilo za uspešno celovito projektiranje. Uporaba kompleksne matrične metode je primerna za projektiranje strukture vojaških sil zlasti pri oblikovanju makro- in mikromodela organiziranosti.

Metode operacijskih raziskav se pri projektiranju organiziranosti uporabljajo množično. Sodobnega projektiranja strukture sil brez uporabe metod in modelov operacijskih raziskav tako rekoč ni mogoče uspešno izvesti. Pri tem je treba poudariti metode vojnih iger, zlasti vojne igre za potrebe načrtovanja, nadalje metode simulacij kot ene od najmočnejših analitičnih orodij na področju operacijskih raziskav in posebne modele za simulacijo obrambnih izdatkov in za simulacijo učinkovitosti strukture sil.

Razvoj operacijskega raziskovanja, zlasti modeliranja in metod simulacij, je omogočil razvoj metod za kvantitativno merjenje modernizacije vojaških sil in njihove učinkovitosti. Do danes so bile razvite številne metode, ki za vrednotenje uporabljajo ocenjevalne modele oborožitvenih sistemov in veliko spremljevalnih modelov za ocenjevanje drugih kvalitativnih vidikov vojaških sil, kot so osebje, poveljevanje in kontrola, logistika ipd.

Modeli zagotavljajo statične indikatorje sposobnosti in zmogljivosti vojaških sil, temelječih na značilnostih in količini posameznega orožja in izraženih kot numerični rezultat (točke bojne sposobnosti in zmogljivosti). Individualno vrednotenje posameznih oborožitvenih sistemov (letala, rakete, topovi, tanki in druga oklepna bojna vozila, mornariška bojna sredstva idr.) se izvaja po njihovih tehničnih zmogljivostih (vrsta, hitrost, nosilnost, domet, manevrske sposobnosti ipd.), pa tudi po sposobnosti zadevanja in uničenja ciljev ter zmožnosti uporabe in vodenja sistema. Relativna pomembnost teh značilnosti posameznih oborožitvenih sistemov se računa s težnostnimi dejavniki - ponderji, uporabljajoč metodo Delphi in metodo AHP (Analytic Hierarchy Process). Posamezne vrednosti oborožitvenih sistemov lahko uporabimo posamično ali jih kombiniramo za izdelavo zbirnih teoretičnih zmožnosti sil. Za nekatere analitične primere pa teoretične sposobnosti in zmogljivosti oborožitvenih sistemov ali teoretične sposobnosti in zmogljivosti sil niso zadostne. Zato ocenjevanje realne sposobnosti in zmogljivosti sil zahteva tudi vrednotenje neotipljivih (neoborožitvenih) vidikov vojaških sil, kot so poveljevanje in kontrola ter delovanje sistemov C4I, logistična organizacija in podpora ter vzdržljivost sil, zmožnost mobilizacije in razvoja sil ter struktura sil in alokacija virov. Za te potrebe so razviti posebni modeli, ki omogočajo bolj realno ovrednotenje bojne sposobnosti in zmogljivosti. 


\section{DRMM - MODEL ZA PODPORO PROJEKTIRANJA PREOBLIKOVANJA STRUKTURE SIL}

Defense Resource Management Model, skrajšano DRMM, v prevodu model upravljanja obrambnih virov, je računalniški model, ki so ga razvili za potrebe podpore načrtovanja na obrambnem ministrstvu $Z^{2} A^{13}$. To analitično orodje je namenjeno podpori načrtovanja obrambnih virov in projektiranju vojaške strukture sil, torej pri defense planningu in force planningu.

Predstavitev modela za podporo projektiranja je pomembna zato, ker opozarja na metodološke posebnosti pri projektiranju preoblikovanja strukture sil vojske in kaže, kako je treba spremeniti dosedanjo prakso pri snovanju organiziranosti tako, da bo izhajala iz stroškov in razpoložljivih virov ter bo glede na navedeno uresničljiva.

Model je orodje za analiziranje (študijo) na makro ravni in za podporo odločanju glede na stroške in sposobnost sil ter omogoča preveritev alternativ strukture sil skozi njihovo večletno načrtovalno obdobje. Bistvo DRMM je, da je za predlagani model organiziranosti mogoče ovrednotiti integrirano bojno sposobnost in zmogljivost sil glede na stroške, in to glede na nasprotnika (grožnjo) ali na alternativni model organiziranosti - alternativno strukturo. Model omogoča alokacijo stroškov in ocenjevanje bojne zmogljivosti in sposobnosti sil.

Z DRMM vrednotimo integrirano sposobnost sil na podlagi sistema točkovanja. Stroškovna analiza omogoča ocenitev stroškovnih prednosti nakupov različnih MTS $\mathrm{v}$ različnih programih razvoja sil. Z modelom lahko ovrednotimo tudi trenutno stanje sil, torej ga lahko uporabimo tudi za podporo ocenjevanja in analiziranja obstoječe organiziranosti.

Model omogoča kreiranje in modificiranje glavnih značilnosti strukture sil, operativne uporabnosti oborožitve in opreme, usposabljanja, vojnih rezerv, upravljanja in financiranja, s tem pa podpira dokončno oblikovanje (elaboriranje) projekta preoblikovanja ob koncu tretje faze projektiranja. Ko postavimo večletno projekcijo strukture sil in stroškov, model zagotavlja uporabniku velik spekter tabel in diagramov, ki predstavljajo različne vidike strukture sil oziroma njihovih specifičnih elementov, posameznih enot, tipov opreme, kategorij proračuna, stroškovnih mest ipd., to pa je kot podlaga uporabno pri izdelavi načrta za izvedbo preoblikovanja $\mathrm{v}$ četrti fazi projektiranja.

Program DRMM deluje na računalnikih, ki so skladni z IBM v okolju Windows. Komponenti DRMM sta modul sil in modul stroškov.

\footnotetext{
${ }^{13}$ To je orodje za podporo PPBS (Planning, Programming and Budgeting System) - sistema za načrtovanje, programiranje in proračunsko financiranje na obrambnem ministrstvu $Z D A$.
} 
DRMM modul sil obsega podatke, ki jih lahko razdelimo na te glavne skupine:

1. enote $v$ naši strukturi po ravneh,

2. oprema, s katero razpolagamo po vrstah in količini, glede na mirnodobno delovanje in kategorije, katerim pripada ta oprema,

3. osebje v strukturi sil po tipih osebja in plačilnih kategorijah,

4. viri, ki obsegajo človeške in materialne vire $v$ tako imenovanih vojnih rezervah.

Če želimo primerjati strukturo sil glede na strukturo sil nasprotnika, glede na grožnjo, s katero se spoprijema država, je treba vnesti v modul tudi sestavo nasprotnikovih sil.

DRMM uporablja metodologijo vrednotenja bojne sposobnosti in zmogljivosti opreme tako, da določi vsakemu tipu opreme v popisu določeno število (bojnih) točk. ${ }^{14}$ Sposobnost določene strukture sil je dobljena s seštevanjem (združevanjem) vseh točk za opremo v popisu. Ta seštevek točk pomeni statično vrednost sposobnosti določene strukture sil. Opremo, ki predstavlja nebojni del (npr. tovorna vozila, pontonski mostovi, ipd.), je treba prav tako vnesti v popis, saj predstavlja stroške, čeprav nima točk za bojno sposobnost in zmogljivost. To velja tudi za infrastrukturne objekte, čeprav le redki od njih dobijo točke za bojno sposobnost in zmogljivost, predstavljajo pa velik delež stroškov, ki so povezani z njimi. Model lahko prikaže zmanjšano sposobnost opreme glede na pomanjkanje virov ali glede na starost opreme.

Obstajajo štiri kategorije točk bojne sposobnosti in zmogljivosti opreme, in sicer glede na formacijo, dejansko stanje popolnitve, sposobnost za delovanje in učinkovitost. Model prikazuje skupno število točk po kategorijah.

DRMM stroškovni modul vključuje vse mirnodobne stroške (stroške delovanja):

1. stroške strukture sil,

2. stroške bojne pripravljenosti,

3. stroške investicij in

4. stroške vzdrževanja stanja.

V stroškovnem modulu oblikujemo stroške na enoto tako, da jih gradimo od spodaj navzgor, pri alokaciji virov pa tako, da stroške zajemamo od zgoraj navzdol. Pristop od spodaj navzgor zagotavlja, da so potrebe posameznih enot upoštevane v modeliranju ter prikazane možnosti proračunskega pokritja. DRMM omogoča upoštevanje inflacije, tako da lahko stroške prikažemo tudi s tega vidika. Ko vnesemo v baze podatkov DRMM vse podatke o obstoječem stanju sil ter predlagano strukturo sil v prihodnosti, nam model omogoča stroškovno preračunavanje. To zagotavlja uporabniku možnost ocenjevanja in primerjavo stroškov obstoječe strukture sil z alternativnimi.

\footnotetext{
${ }^{14}$ Za točkovno podlago uporablja orodje Technique for Assessing Comparative Modernization (TASCFORM) ali Equipment Potential capability Comparison (EPOCC).
} 
Podatkovne baze DRMM sestavljajo štiri baze:

1. baza podatkov o zgradbi sil,

2. baza podatkov o zgradbi stroškov,

3. baza podatkov o silah - enotah in

4. baza podatkov o stroškovnih dejavnikih.

Analiza (študija) DRMM je zasnovana kot stopenjski in delni-po delih ponavljajoči se postopek. Analiza obsega oblikovanje in razvoj baz podatkov, organiziranje aparata za izvedbo analize ter organiziranje in izvedbo postopka analize. Navedel sem že, da analiza podpira postopke tretje faze projektiranja preoblikovanja strukture sil.

Aparat za izvedbo analize obsega skupino za izvedbo, računalniško opremo in programsko orodje modela ter podporo z vidika zagotovitve baz podatkov. Skupina za izvedbo analize je sestavljena iz vodstva in potrebnega števila analitikov ter je funkcionalno organizirana. Po navadi se določi še skupina za vodenje analize (top menedžment) in ta opredeli izhodišča in zahteve za snovanje alternativ ter sprejema odločitve. Temeljni pogoj za izvedbo analize so potrjeni razvojni dokumenti oziroma načrti in strategija za preoblikovanje oziroma zamisel za izvedbo preoblikovanja strukture sil.

Potek analize obsega:

1. vzpostavitev osnovnega primera - modela organiziranosti,

2. vnos sil nasprotnika - opcije,

3. analizo osnovnega primera,

4. razvoj in analizo alternativ,

5. oblikovanje izdelkov analize,

6. predstavitev izdelkov analize in dopolnitev analize,

7. končno poročilo.

1. Vzpostavitev osnovnega primera je začetni del analize; podskupini za stroške in sile razvijeta osnovni primer oziroma model organiziranosti. Po vnosu podatkov za osnovno leto, in sicer za enote, osebje, opremo, vire in stroške, to leto premočrtno prekopiramo v druga leta in vnesemo vse spremembe v strukturi sil, osebju, modernizaciji, opremi in virih. Ta del torej obsega pridobivanje in vnašanje podatkov, ki so karakteristični elementi trenutnega in večletnega nacionalnega načrta razvoja strukture sil. Osnovni primer je večletni posnetek uradno odobrenega stanja strukture sil in razvoja strukture sil v prihodnje. Postavitev osnovnega primera je temeljni pogoj za razvoj alternativ in analize strukture sil glede na sposobnost in stroške.

2. Vnos sil nasprotnika (opcije) obsega oblikovanje podatkov o strukturi sil nasprotnika in vnašanje podatkov v model. Namen podatkov o silah nasprotnika je, da zagotovimo primerjavo sil kot realno ocenitev vojaške sposobnosti. Namesto podatkov o nasprotniku pa lahko uporabimo izmišljene podatke (opcije) oziroma podatke o silah, s katerimi bi želeli primerjati naš osnovni primer - model organiziranja. 
3. Analiza osnovnega primera poteka z analitičnim orodjem v modelu. DRMM zagotavlja tabelarne in grafične izdelke, ki jih uporabljamo kot pomoč za ocenitev osnovne strukture sil glede na bojno sposobnost in zmogljivost ter glede na mirnodobne stroške. Osnovni primer je referenčna točka za analizo sil in stroškovno analizo ter opis sposobnosti sil in stroškov v prihodnjih fiskalnih obdobjih. Stroškovna analiza omogoča zasledovanje stroškov časovno skozi pojavljajoča se obdobja in določanje proračunskih učinkov glede na potrebe po usposabljanju in opremljanju sil. Model DRMM zagotavlja tudi vpogled v specifične stroške, ki se pojavljajo (npr. delež stroškov, namenjen posamezni zvrsti ali rodu oboroženih sili, delež po namembnosti sil in dejavnostih ali stroške po proračunskih postavkah). Analitično orodje znotraj stroškovnega modula DRMM lahko izvaja analize kot npr. določanje časovnega obdobja, ki je potrebno, da zamenjamo letalo ali tank glede na sedanje in na pričakovane izdatke za nabavo, pripravo kadra, infrastrukture idr. Analiza sil daje odgovore na vprašanja o bojni sposobnosti in zmogljivosti sil ter razpoložljivosti vojske. Z izdelki DRMM in izkušnjami pri opredeljevanju in analiziranju vojaških sil podpremo opredelitev ključnih elementov osebi, ki odloča.

4. Razvoj in analiza alternativ se osredotočita na identifikacijo problemskih področij, ki jih je treba detajlno preučiti pri postavitvi alternativ. Namen razvoja alternativ je doseganje izboljšav na določenih področjih glede na osnovni primer - model organiziranja. Tako izvajamo nov ponavljajoč se cikel za kreiranje modela organiziranosti. Vključevanje stroškov v osnovni primer in odnos med našimi silami in silami nasprotnika je treba podrobno preučiti ter oceniti dejansko sposobnost naših sil. Če ugotovimo primanjkljaj $\mathrm{v}$ sposobnosti sil, je treba $\mathrm{v}$ novih alternativah preučiti te slabosti in jih kompenzirati ali poudariti potrebo po odločitvi o povečanem tveganju. Alternative lahko vključujejo prestrukturiranje sil, modernizacijo opreme, stopnjo virov, preusmeritev osebja, prelokacijo finančnih virov med področji proračuna. Večinoma razvijamo več kot eno alternativo znotraj usmeritev ali razvojne strategije in dodeljenega proračuna. Naprej se postopek ponavlja, analiziramo nove alternative strukture sil. Glavna razlika med analizami alternativ modelov organiziranosti in analizo osnovnega primera - modela organiziranosti je, da lahko alternative primerjamo tako glede na nasprotnikove sile kot tudi na druge alternative in na osnovni primer. Večina izdelkov DRMM dovoljuje predstavitev osnovnega scenarija nasprotnikovih sil in alternativ $\mathrm{v}$ istem poročilu grafično in tabelarno.

5. Oblikovanje izdelkov zagotavlja output v izvedbi analize. Temeljni namen oblikovanja izdelkov je priprava in predstavitev kazalcev za podporo odločanja. Vsi izdelki se ob koncu oblikujejo v integrirani dokument.

6. Pri predstavitvi izdelkov analize predstavimo izdelke analize in priporočila za odločanje skupini za vodenje analize ali drugemu vodilnemu osebju. Predstavitev izdelkov je lahko delna, lahko že poteka ali je končna. Po delnih predstavitvah se po navadi opravijo dopolnitve na podlagi novih usmeritev in zahtev. Seveda se dopolnitev lahko opravi tudi po končni predstavitvi izdelkov analize. Končna predstavitev vsebuje priporočila za odločanje in ta se potrdijo ali zavrnejo. 
7. Analiza se konča z oblikovanjem poročila o izvedbi in delu skupine za izvedbo analize ter s predajo poročila in izdelkov organizacijski enoti za projektiranje oziroma naročniku.

Izdelki analize DRMM predstavljajo široko paleto izpisov glede strukture sil in podatkov o stroških po izbiri uporabnika. DRMM zagotavlja dve obliki izpisov, in sicer tabelarne in grafične. Oblike izpisov so postavljene tako, da pospešijo pregled napak pri opredelitvi strukture sil ter podpirajo analize in ocenjevanje strukture sil.

Izdelek o strukturi sil je lahko: tabelarno poročilo o enotah, tabelarno poročilo o opremi, poročilo OPTEMPO (operativni tempo), tabelarno poročilo o virih, tabelarno poročilo o osebju, graf o točkah sposobnosti, ki predstavlja najmočnejši del za podporo analizam in ocenjevanju strukture sil, in graf o naraščanju sposobnosti.

Izdelek stroškov je lahko: pregled stroškovnih dejavnikov, poročilo o stroškovni različnosti, poročilo o rezultatu stroškov, specialno poročilo o stroških za osebje, za opremo in za nakupe opreme, poročilo o stroškovnem poizvedovanju in grafični prikaz stroškov.

Veliko izdelkov ima možnost za prenos ali zapis v elektronski obliki v druge programske pakete in to omogoča analitikom nadaljnje analiziranje podatkov, prenos podatkov v druge programe ter uporabo podatkov za druge oblike poročil in grafov.

\section{Kakšna je uporabnost in katere so pomanjkljivosti DRMM?}

DRMM je s svojo metodologijo primerjanja stroškov in sposobnosti enot s katero koli strukturo sil učinkovito analitično orodje. DRMM z modulom stroškov in sil omogoča fleksibilno analiziranje stroškov in sposobnosti kot osrednjim vprašanjem defense in force planninga. Uspešno lahko podpre oblikovanje modelov organiziranosti in snovanje projekta preoblikovanja strukture sil pri projektiranju.

DRMM omogoča kreiranje alternativnih scenarijev, povezanih s strukturo sil, stopnjo usposobljenosti, tipom in stopnjo modernizacije ter z vojnimi rezervami, in s tem opredelitev njihovih učinkov na obrambni proračun. Če želimo prikazati trende, lahko te učinke analiziramo skozi večletno obdobje. DRMM je učinkovito orodje, če se obvladuje metodologija in razpolaga $z$ ustreznim aparatom in predvsem usposobljenim kadrom. Učinkovito je takrat, kadar je ustrezno integrirano $\mathrm{v}$ projektiranje preoblikovanja strukture sil in obrambnega načrtovanja, ni pa nadomestilo zanj. DRMM ni projektiranje, temveč je podpora projektiranja.

Ima pa DRMM tudi omejitve in pomanjkljivosti. Največ organizacijskih težav pomeni zagotovitev ustrezne primerjave strukture sil (nasprotnika), zlasti takrat, kadar je natančno predvidevanje grožnje težje izvedljivo. DRMM ne pove uporabniku, kako najbolje alocirati vire, in ne more zamenjati vojaške presoje ter nadomestiti odločanja pri izbiri najboljše alternative. 
Model primerja in vrednoti le določene vrste opreme (težke oborožitve). Modul sposobnosti sil v DRMM upošteva le dejavnike, ki vplivajo na sposobnost in zmogljivost sil. Sistem točkovanja za sposobnost opreme je narejen po merilu ocenjevanja sposobnosti sil v okolju srednje Evrope. Dopolnitev vrednotenja bojne sposobnosti in zmogljivosti je sicer možna, vendar je zahtevna. Točkovni sistem ne zagotavlja ustreznega vrednotenja lahkih sil. Model tako zahteva dodatno podporo vrednotenja bojne sposobnosti in zmogljivosti zlasti za pehotne enote.

Model ne more $\mathrm{v}$ celoti vrednotiti prispevka elementov, kot so poveljevanje in kontrola, zveze, informatika, elektronsko bojevanje, psihološko delovanje, prelociranje sil. Prav tako ne upošteva vpliva doktrine, morale in drugih dejavnikov pripravljenosti sil.

Model je narejen na statični osnovi. DRMM ni dinamični model bojevanja (warfare) in ni vojna igra (wargame). Za dosego celovitosti in učinkovitosti pri oblikovanju modelov organiziranosti je zato treba poseči še po dodatnih modelih za simulacije in vojno preigravanje.

\section{PREOBLIKOVANJE SLOVENSKE VOJSKE - SEDANJI IZZIV ZA PRIHODNOST}

Dosedanji razvoj in snovanje vojske za prihodnost sta tudi pri nas predmet številnih strokovnih, pa tudi političnih obravnav in to samo potrjuje pomembnost in aktualnost teh vprašanj.

Osrednja značilnost dosedanje prakse je bila, da se je velikokrat projektiralo in odločalo z neustrezno podporo ali brez ustrezne podpore, ki mora spremljati politične in strokovne odločitve in postopke oblikovanja razvojnih programov, ter da je bil pri projektiranju strukture sil najpogosteje uporabljen ad hoc pristop, usmerjen v delne ali kratkoročne rešitve.

Menim, da je bil temeljni problem pri dosedanjem projektiranju preoblikovanja strukture sil Slovenske vojske v nejasnih ciljih in viziji, v predimenzionirani zasnovi obsega, v neizoblikovani strategiji preoblikovanja in v prepogostem spreminjanju težišč. Zaradi tega je bil stroškovni del projektiranja močno omejen ali zapostavljen. $\mathrm{S}$ spreminjanjem težišč preoblikovanja in razvojnih prioritet pa se je projektiranje strukture sil vedno znova vračalo na začetek in bilo ujeto v začarani krog s skromno realizacijo projektov. Dosedanje preoblikovanje strukture sil je potekalo po jedrih, del teh projektov preoblikovanja pa ni bil končan. Sistem dolgoročnega načrtovanja financiranja in razvoja na obrambnem področju, ki je veljal v nekdanji skupni državi, je bil leta 1991 opuščen, novi pa dolgo ni bil postavljen.

Ministrstvo za obrambo je leta 1997 znotraj dvostranskega sodelovanja z obrambnim ministrstvom (MOD) ZDA dobilo pomoč za uveljavljanje defense planninga in force planninga. Poleg svetovanja glede organizacije defense in force planninga je 
bilo prevzeto orodje DRMM, usposobljen je bil tim za delo na njem in izvedena je bila analiza. Analiza s tem orodjem je bila ponovno izvedena tudi v drugi polovici leta 2001 in končana v prvem četrtletju 2002. Razpoložljiva programska podpora za defense in force planning je na Ministrstvu za obrambo in v Slovenski vojski dobra. Poleg modela DRMM, ameriške metodologije PPBS, programskega orodja za vrednotenje bojne sposobnosti in zmožnosti ameriškega podjetja TASC (The Analytic Science Corporation), ki je razvilo tehnike za primerjalno ocenjevanje modernizacije sil TASCFORM (Technique for Assesing Comparative Force Modernization) in EPOCC (Equipment Potential Capability Comparison), obstajajo še bojni simulacijski modeli HORUS ${ }^{15}$ in JANUS ${ }^{16}$, s katerimi razpolaga Oddelek za raziskave in simulacije v Centru vojaških šol, in drugi.

Zagotovo bi se $\mathrm{z}$ boljšo izrabo dosegljive podpore ${ }^{17}$ lahko izognili večini pomanjkljivosti pri dosedanjem projektiranju strukture sil. Usposobljenost ljudi za projektiranje preoblikovanja strukture sil je vsekakor problem.

Strukturne, organizacijske in funkcionalne spremembe $\mathrm{v}$ obrambni in vojaški organiziranosti Republike Slovenije so nujne tudi zaradi sprememb, ki nastajajo s približevanjem EU in Natu. Pri tem Slovenija ne more zagotoviti celovite in časovno neomejene samozadostnosti obrambnega sistema. To že dolgo ni več stalnica tudi $\mathrm{v}$ velikem številu ekonomsko in demografsko močnejših držav.

Potrebe po preoblikovanju strukture in spreminjanju koncepta organiziranosti so razvojne potrebe Slovenske vojske, ki izhajajo iz cilja, da bo učinkovitejša, sodobnejša in primerljiva ter mednarodno povezljiva. Projektiranje preoblikovanja Slovenske vojske intenzivno poteka.

Izhodišča za preoblikovanje strukture sil Slovenske vojske so bila:

1. sprejeti strateški in doktrinarni ter dolgoročni razvojni dokumenti,

2. identificirano obstoječe stanje organiziranosti in analizirani vplivni dejavniki,

3. potrebe po preoblikovanju strukture sil in spreminjanju koncepta mezoorganiziranosti z obstoječimi alternativami,

4. vizija za izvedbo preoblikovanja,

5. zahteve po optimalizaciji strukture in ekonomizaciji prihodnjega modela organiziranosti.

\footnotetext{
${ }^{15}$ HORUS (Heeresmodell f.r Operations Research zur Untersuchung von Strategiefaktoren) je bojni model nemške zvezne vojske in proizvod podjetja IABG iz Ottobruna v Nemčiji. Namenjen je simulaciji boja na ravni bataljon/ brigada/divizija (Savšek, 2000, str. 114).

${ }^{16}$ JANUS je interaktivna računalniška zemeljska dvostranska brigadna simulacija ameriške vojske in proizvod Lawrence Livermore National Laboratoryja iz ZDA (Savšek, 2000, str. 124).

${ }^{17}$ Kljub temu da sta HORUS in JANUS namenjena vojnim igram in bojnim simulacijam, ju lahko uporabimo za pregled vpliva sprememb določenih parametrov bojne sposobnosti in zmožnosti sil ter za preslikavo podatkovnih baz v druge modele bojevanja ali ocenjevanja bojnih zmožnosti. Pomembni pa so tudi taktični kazalci vojne igre. Tako je študijska vaja znotraj vojaške operacijske raziskave (od novembra 2001 do marca 2002), namenjena preveritvi projektirane strukture sil Slovenske vojske do leta 2004, pokazala konceptualne slabosti v ZO in inženirstvu ter opozorila na posebnosti bojiščnih sistemov in zmožnosti brigade Slovenske vojske.
} 
Temeljna izhodišča za projektiranje preoblikovanja strukture sil Slovenske vojske opredeljujeta Obrambna strategija (december 2001) in Splošni dolgoročni program razvoja in opremljanja Slovenske vojske (november 2001). V vlogi strategije preoblikovanja se pojavlja Koncept preoblikovanja Slovenske vojske 2004, ki ga je potrdil minister za obrambo (november 2001). Vizija za izvedbo preoblikovanja temelji na postopnosti izvajanja sprememb, usklajeno z uvajanjem sprememb $\mathrm{v}$ drugih delih obrambnega sistema. Pri projektiranju preoblikovanja strukture sil in načrtovanju razvoja Slovenske vojske izhajamo iz optimalizacije strukture in ekonomizacije, ki temelji na strokovnih podlagah, ob upoštevanju kadrovskih, infrastrukturnih in proračunskih zmožnosti ter dejstvu, da se v sodobnih razmerah uspešnost modernih vojaških organizacij ne meri zgolj po obsegu fizične sile, temveč po odzivnosti in zmožnosti sil.

Projektiranje preoblikovanja strukture sil je zasnovano na realno dosegljivih finančnih in kadrovskih zmožnostih, težišče pa je povečanje kakovosti in zmanjševanje fizičnega obsega sil. Upoštevali smo metodološka dognanja in zahteve sistematičnega pristopa, o katerih je govor tudi v tem sestavku. Žal je bil stroškovni del projektiranja (programiranja) velikokrat sekundarnega pomena.

Funkcionalna povezanost in odvisnost vojaške obrambe od preostalega dela obrambnega sistema zahtevata sočasno načrtovanje in usklajeno izvajanje sprememb vseh sestavin. Zaradi tega projektiranje preoblikovanja strukture sil Slovenske vojske ne sme biti edino področje sprememb in ne more biti nepovezan proces. Zato so usklajene spremembe in reforme v obrambnem sistemu neizogibne. Lahko jih sicer odlagamo, ne moremo pa se jim izogniti zaradi sedanjega stanja in značilnosti ter trendov v širšem okolju. To potrjujejo dogajanja v številnih državah, v katerih pripravljajo in izvajajo organizacijske spremembe ne samo v strukturah oboroženih sil, temveč oblikujejo nove koncepte ter iščejo rešitve kot odgovore za sodobne nevarnosti in izzive. Za organizacijske spremembe je značilna stalnost. Zato se tudi v primeru Slovenske vojske pojavlja dilema, kako pravilno dimenzionirati cikle preoblikovanja, da bi zagotovili stalnost sprememb in se izognili stalnim reorganizacijam brez pravih učinkov in $\mathrm{s}$ tem zmanjševanju pripravljenosti za spremembe.

Sklep Spreminjanje in dopolnjevanje vojaške organiziranosti spadata med osrednje razvojne izzive in dejavnosti na obrambnem področju v mnogih državah. Dejstvo je, da se z vprašanji projektiranja nove strukture in preoblikovanja organizacijskih modelov intenzivno ukvarjajo organizacijske enote za defense in force planning.

Pri iskanju odgovorov na vlogo vojske v spremenjenih političnih in varnostnih razmerah ter rešitev glede reorganizacije obrambnih sistemov in preoblikovanja oboroženih sil in sprejemanja odločitev glede njihovega drugačnega popolnjevanja ter spremenjenih operativnih zahtev pri uporabi vojaške sile imata izredno pomembno vlogo metodologija in podpora načrtovanja ter projektiranja. 
Prejšnja ugotovitev velja tudi za Slovensko vojsko, predvsem zaradi omejenosti njenih virov. V mednarodne vojaške integracije lahko Slovenska vojska prispeva vojaške sile in ljudi, ki bodo po obsegu primerni zmožnostim. Predimenzioniranje tega prispevka pri projektiranju strukture sil lahko negativno vpliva na funkcioniranje celotnega sistema.

Dileme, ali so izbrane prave rešitve, so bile in bodo stalnica pri projektiranju modelov organiziranosti. Ni se jim mogoče izogniti niti pri projektiranju preoblikovanja strukture sil Slovenske vojske. Sodobne metode in orodje za podporo projektiranja lahko te dileme občutno zmanjšajo.

\section{Literatura}

1. Allied joint doctrine, AJP 01(A), 1998: NATO; Military agency for standardisation (MAS) chapter 2-Principles.

2. Boland, Frank: Force planning in the new NATO, NATO review, No. 3, Autumn 1998, p. $32-35$.

3. Brassey's multilingual military dictionary, 1989: Brassey's (US), Washington, D.C.

4. Defense Resource Management Model (DRMM), Users' Manual, 2000: Department of defense USA, Washington.

5. Defence restructuring and conversion - Sociocultural aspects, edited by Ljubica Jelušič and John Selby, 1999: European Commission, Directorate-General Research, Brusseles, p. 52-63, 183-198, 183-198.

6. Dictionary of military terms, by Greenhill Books, 1995: Butler \& Tanner Ltd., London.

7. International Military and Defense Encyclopedia, 1993: Brassey's (US), Washington, D.C. Volume 5 P-S, p. 2030-2044, 2144-2153.

8. Ivanko, Štefan, 1999: Urejenost podjetja - strukture in procesi, Visoka šola za management, Tiskarna Stražar, Koper.

9. Ivanko, Štefan, 1991: Razvoj in spreminjanje organizacije, Visoka šola za podjetništvo, Portorož.

10. Lah, Ivan, 1995: Operacijsko raziskovanje za častnike in obramboslovce, Ministrstvo za obrambo, I. uprava, Tiskarna Formatisk, Ljubljana.

11. Lipovec, Franjo, 1987: Razvita teorija organizacije, Založba Obzorja, Maribor.

12. Miloševice, Novak, 1989: Projektovanje istraživanja u ratnoj veštini, Vojnoizdavački $i$ novinski centar, Vojna štamparija, Beograd.

13. Možina, Stane, et al.,1994: Management, Didakta, Radovljica, Ivanko, Štefan: poglavje 10 - Osnove organiziranja in poglavje 11 - Projektiranje organizacije, str. 373-438.

14. Opis modela za podporo pri strateškem odločanju-DRMM, 1999: Generalštab Slovenske vojske - uredil Dobran Božič, Ljubljana.

15. Rozman, Rudi, et. al., 1993: Management, Gospodarski vestnik, Ljubljana.

16. Savšek, Tomaž, 2000: Sodobni vojaški simulacijski sistemi-operacijske raziskave, vojne igre in bojne simulacije, Generalštab Slovenske vojske, Center vojaških šol, Delo Tiskarna, Ljubljana.

17. Sikavica, Pere, 1991: Modeliranje organizacijske strukture poduzecea, Informator, Zagreb.

18. Šteiner, Alojz, 2000: Preoblikovanje strukture sil Slovenske vojske - študija primera, Zaključna naloga, Poveljniško-štabna šola, Generalštabni program, Ljubljana.

19. The official Dictionary of military terms, second edition 1997: Department of defense, USA, The joint chiefs of stab, Global professional publications, Washington, D.C. 
20. The TASCFORM methodology, 2000: A technique for assessing comparative force modernisation (seventh edition), The office of the assistant secretary of defense, USA, The Analytic Sciences Corporation (TASC), Arlington, Virginia.

21. Vila, Antun: Reinženiring - nova organizacijska revolucija, Gospodarski vestnik, št. 28 , 29 in 30, julij 1997. 